\title{
A correction formula for neuron-specific enolase measurement in hemolyzed neonatal serum samples
}

\author{
QIANG WANG ${ }^{1-3^{*}}$, GUANGRONG WANG ${ }^{2 *}$, XIAOLAN LU ${ }^{2}$, XIAOLAN GUO ${ }^{1}$, QIN DU $^{2}$, \\ FANG LIN $^{1}$, QUMING FAN ${ }^{1}$, GUOYUAN ZHANG ${ }^{2}$ and DONGSHENG WANG ${ }^{2}$ \\ ${ }^{1}$ Faculty of Laboratory Medicine, North Sichuan Medical College; \\ ${ }^{2}$ Department of Laboratory Medicine, Affiliated Hospital of North Sichuan Medical College; \\ ${ }^{3}$ Center for Translational Medicine, North Sichuan Medical College, Nanchong, Sichuan 637000, P.R. China
}

Received November 1, 2017; Accepted March 7, 2018

DOI: 10.3892/br.2018.1081

\begin{abstract}
As a specific biomarker in neonatal hypoxic-ischemic encephalopathy (HIE), the measurement of neuron-specific enolase (NSE) has been advocated as a predictor of outcome in neurological injury. However, the measured levels of NSE may be influenced by hemolysis. In the current study, the change in the concentration of NSE in serum was measured by chemiluminescence prior to and following the addition of individual frozen and thawed red blood cells from 86 neonates that were collected within $24 \mathrm{~h}$ of birth. The changes in the concentration of NSE were compared with the changes in the concentration of hemoglobin $(\mathrm{Hb})$, measured by the hemoglobin cyanide (HiCN) method, to establish a correction formula. The performance of the correction formula was evaluated by comparing the corrected concentration of NSE using the individual constants and the correction formula. The average individual constant of NSE from the 86 hemolyzed neonatal serum samples was $25.15 \pm 3.94 \mathrm{mg} / \mathrm{g} \mathrm{Hb}$. The concentration variation between NSE and $\mathrm{Hb}$ in neonatal sera could be described by the equation $\Delta \mathrm{NSE}_{\text {serum }}=1.8594+24.0670$ $\mathrm{x} \Delta \mathrm{Hb}_{\mathrm{HiCN}}\left(\mathrm{r}^{2}=0.8045, \mathrm{P}<0.001\right)$. There was no statistically significant difference in the NSE corrected results between the individual constant group and the correction formula group $(\mathrm{Z}=-1.645, \mathrm{P}=0.100)$. The linear regression formula of $\mathrm{Hb}$ measured with the instrumental method compared with the HiCN method was $\mathrm{Hb}_{\text {instr }}=0.9816 \times \mathrm{Hb}_{\mathrm{HiCN}}+0.5596\left(\mathrm{r}^{2}=0.9924\right.$,
\end{abstract}

Correspondence to: Dr Dongsheng Wang, Department of Laboratory Medicine, Affiliated Hospital of North Sichuan Medical College, 63 Wenhua Road, Nanchong, Sichuan 637000, P.R. China E-mail: wangdongshengnc@163.com

*Contributed equally

Abbreviations: HIE, hypoxic-ischemic encephalopathy; NSE, neuron-specific enolase; $\mathrm{Hb}$, hemoglobin; HiCN, hemoglobin cyanide; RBCs, red blood cells

Key words: neuron-specific enolase, neonatal hemolysis, correction formula
$\mathrm{P}<0.001)$. Based on these regression analyses, the correction formula for NSE in hemolyzed neonatal serum was determined as $\mathrm{NSE}_{\text {corr }}=\mathrm{NSE}_{\text {meas }}-24.0670 \times \mathrm{xb}_{\mathrm{HiCN}}-1.8594$ or $\mathrm{NSE}_{\text {corr }}=$ $\mathrm{NSE}_{\text {meas }}-24.5181 \times \mathrm{Xb}_{\text {instr }}+11.8609$. In conclusion, hemolysis has a substantial influence on the accurate measurement of NSE in neonatal serum samples. For hemolyzed neonatal serum samples, correcting the NSE results using a correction formula is essential to evaluate the severity of neonatal hypoxic ischemic encephalopathy.

\section{Introduction}

Hypoxic-ischemic encephalopathy (HIE) secondary to perinatal asphyxia remains a major cause of neonatal mortality and morbidity worldwide $(1,2)$. The incidence of HIE ranges from 1 to 3 per 1,000 full-term infants and is present in almost $60 \%$ of premature newborns (3-5). Approximately $15-20 \%$ of affected newborns succumb within the postnatal period, and an additional $25 \%$ develop severe and permanent neuropsychological handicaps, including cerebral palsy, seizures, visual impairment, mental retardation, learning disabilities and epilepsy (5).

Neuron-specific enolase (NSE) belongs to the family of enolase enzymes present in all tissues and organisms capable of glycolysis (6). Enolases consist of three subunits $(\alpha, \beta$, and $\gamma)$ encoded by separate genes. These subunits may combine to form five different isoenzymes: $\alpha \alpha, \alpha \beta, \alpha \gamma, \beta \beta$ and $\gamma \gamma$ (6). NSE, comprised of $\gamma \gamma$ homodimers and $\alpha \gamma$ heterodimers, is widely distributed in central nervous system neurons and amine precursor uptake and decarboxylation cells (7). As a marker of neuronal cell death, the serum concentration of NSE is associated with the degree of HIE and may be used to evaluate the severity and outcome of HIE (8-11). According to receiver operating characteristic curves, serum concentrations of NSE above $40 \mathrm{mg} / \mathrm{l}$ obtained between 4 and $48 \mathrm{~h}$ after birth may distinguish infants with no or mild HIE from infants with moderate or severe HIE; additionally, serum concentrations of NSE at a cut-off value of $45.4 \mathrm{mg} / \mathrm{l}$ may distinguish infants with poor outcomes from infants with normal outcomes (11).

NSE is present in substantial levels in the brain and at lower levels in platelets, red blood cells (RBCs) and the kidney, and may be differentiated from non-neuronal enolase (NNE), 
which is present in substantial levels in the brain, liver, lung, muscle, testis and platelets and at lower levels in RBCs, through the use of targeted immunoassays (12). As platelets and RBCs contain NSE, hemolyzed samples cannot be tested for NSE. However, neonatal blood specimen collection is prone to hemolysis due to the relatively small size of blood vessels in newborns, and repeated blood sampling is difficult to perform. Therefore, the present study investigated the effect of neonatal serum hemolysis on the detection of NSE and whether the use of a correction formula may aid to reduce these effects.

\section{Materials and methods}

Study subjects. A total of 86 serum samples were collected from newborns, including 54 males and 32 females, within $24 \mathrm{~h}$ of birth at the Affiliated Hospital of North Sichuan Medical College (Nanchong, China) between March 2015 and October 2015. Total bilirubin results of 588 newborns ( 375 males and 213 females) within $120 \mathrm{~h}$ of birth, and the time of phlebotomy time after the birth of 530 newborns (328 males and 202 females) for NSE detection, were collected retrospectively at the Affiliated Hospital of North Sichuan Medical College between March 2015 and July 2015. The hemoglobin (Hb) content of blood samples from 280 newborns (163 males and 117 females), recruited from the Affiliated Hospital of North Sichuan Medical College between March 2015 and May 2015, were measured within $24 \mathrm{~h}$ of birth and classified into different levels to understand the distribution characteristics of total bilirubin, phlebotomy time following birth for NSE detection and $\mathrm{Hb}$ content in neonatal serum samples. All samples were tested for corresponding assays within $2 \mathrm{~h}$ of collection.

$H b$ standard curve for hemolyzed neonatal serum samples. Absorbance values at $540 \mathrm{~nm}$ of a standard solution of $\mathrm{Hb}$ (Tianjin Institute of Modern High-Tech Research Center, Tianjin, China) at concentrations of 50, 100, 150 and $200 \mathrm{~g} / 1$ were measured in a UV-Vis spectrophotometer (Beijing Purkinje General Instrument Co., Ltd., Beijing, China). A standard curve for whole blood was established by plotting the absorbance values versus the $\mathrm{Hb}$ content. The whole-blood samples of 10 randomly selected newborns ( $\mathrm{n}=280$ group) were mixed; $20 \mu 1$ of this mixed blood sample was added to $5 \mathrm{ml}$ Van Kampen and Zijlstra solution (Tianjin Institute of Modern High-Tech Research Center), and the absorbance value of the mixture was measured at $540 \mathrm{~nm}$ within 5-15 min at room temperature. The $\mathrm{Hb}$ content of the mixed whole-blood samples was obtained using the standard curve for whole blood. Concentrations of $\mathrm{Hb}$ of 2, 4, 6 and $8 \mathrm{~g} / \mathrm{l}$ were diluted in physiological saline; $100 \mu \mathrm{l}$ of this diluted sample was added to $2.5 \mathrm{ml}$ Van Kampen and Zijlstra solution, and the absorbance values of the mixture were also measured at $540 \mathrm{~nm}$ within 5-15 min. A standard curve for the hemolyzed neonatal serum samples was established by plotting the absorbance values versus the $\mathrm{Hb}$ concentration, and the standard curve was used to calculate the $\mathrm{Hb}$ concentration in the neonatal serum samples $(\mathrm{n}=86)$.

Hemolyzed neonatal serum NSE quantitation. Whole-blood samples were collected from newborns $(\mathrm{n}=86)$ within $24 \mathrm{~h}$ of
Table I. Laboratory and clinical features of hemolyzed neonatal serum samples.

Feature Value

Serum total bilirubin, $\mu \mathrm{mol} / 1$, mean $\pm \mathrm{SD}$

$\leq 24 \mathrm{~h}(\mathrm{n}=181)$

$45.9 \pm 13.3$

25-120 h $(\mathrm{n}=407)$

$164.7 \pm 74.6$

Phlebotomy time after birth, no. (\%)

$\leq 24 \mathrm{~h}$

$486(91.70)$

25-120 h

Serum hemoglobin $\mathrm{g} / \mathrm{l}(\leq 24 \mathrm{~h})$, no. (\%)

$\leq 1$

38 (13.57)

1-2

$69(24.64)$

$>2$

$173(61.79)$

SD, standard deviation.

birth, and the sera were isolated by centrifugation at $2,583 \mathrm{xg}$ and $25^{\circ} \mathrm{C}$ for $5 \mathrm{~min}$. The NSE values were measured in serum samples by LIAISONXL chemiluminescence analyzer (DiaSorin S.p.A., Saluggia, Italy) with LIAISON ${ }^{\circledR}$ NSE kit (314561; DiaSorin S.p.A.). For each sample, $200 \mu \mathrm{l}$ RBCs were drawn into a tube, stored frozen at $-80^{\circ} \mathrm{C}$ for $5 \mathrm{~min}$, and thawed completely at room temperature; the freeze-thaw cycle was repeated three times. From each sample tested, $300 \mu 1$ serum was drawn into another tube and mixed with $10 \mu \mathrm{l}$ treated RBCs. Serum was isolated by centrifugation at $2,583 \mathrm{x} \mathrm{g}$ and $25^{\circ} \mathrm{C}$ for $5 \mathrm{~min}$ after mixing, and the NSE results of hemolyzed neonatal serum samples were measured by chemiluminescence.

Hemolyzed neonatal serum Hb quantitation. Samples of $100 \mu \mathrm{l}$ hemolyzed neonatal serum for which NSE concentrations had been determined prior to and following addition of freeze-thawed RBCs were added to $2.5 \mathrm{ml}$ Van Kampen and Zijlstra solution. Absorbance values of the mixtures were measured at $540 \mathrm{~nm}$ within 5-15 min, and $\mathrm{Hb}$ concentrations were calculated according to the $\mathrm{Hb}$ standard curve for hemolyzed neonatal serum samples.

Correlation of hemoglobin cyanide $(\mathrm{HiCN})$ and instrument tests. As described in the National Committee for Clinical Laboratory Standards EP9-A2 document (13), the Hb concentrations of 40 randomly selected hemolyzed neonatal serum samples ( $\mathrm{n}=530$ group) within $24 \mathrm{~h}$ of birth with different degrees of hemolysis (Hb: $0.50 \mathrm{~g}-12.00 \mathrm{~g} / \mathrm{l}$ ) were measured with the HiCN method and a Hb analyzer. The correlation was evaluated between the test results of these two methods.

Statistical analysis. SPSS version 18.0 (SPSS, Inc., Chicago, IL, USA) was used to establish the result database and perform the statistical analyses. Measurement data were expressed as the mean \pm standard deviation. The normality of the individual constant between neonatal serum NSE levels relative to the $\mathrm{Hb}$ concentration was evaluated by P-P plot and D'Agostino's test. The Mann-Whitney U test was adopted to compare 

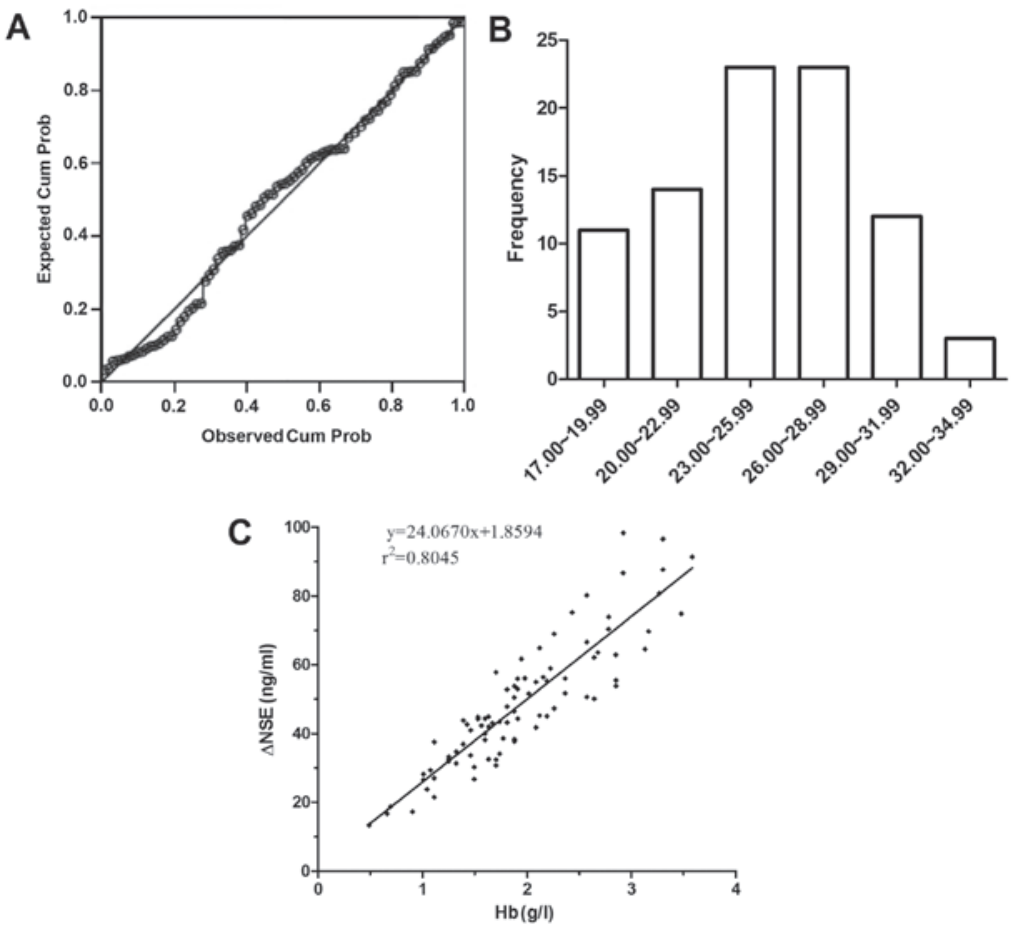

Figure 1. Individual constants of NSE were calculated as the ratios of the changes of the NSE results with the Hb concentration in sera prior to and following addition of individually frozen and thawed RBCs from 86 newborn samples. (A and B) Based upon P-P plot analysis, the individual constants of NSE were normally distributed. (C) Correlation analysis demonstrated that the changes in the concentration of NSE in sera prior to and following the addition of individually frozen and thawed RBCs from 86 neonate samples were significantly correlated with the changes in the concentration of $\mathrm{Hb}\left(\mathrm{r}^{2}=0.8045, \mathrm{P}<0.001\right)$. NSE, neuron-specific enolase; $\mathrm{Hb}$, hemoglobin; RBCs, red blood cells.

corrected NSE levels between the individual constant group $(\mathrm{n}=86)$ and the group following correction formula application ( $\mathrm{n}=86)$, and total bilirubin levels between a 'within $24 \mathrm{~h}$ of birth group' ( $\mathrm{n}=181)$ and 'within $25-120 \mathrm{~h}$ of birth group' $(n=407)$. The Pearson test was utilized for correlation analysis between the adjusted values of the two groups. The Pearson test and linear regression analysis were used to compare the correlation between the levels determined by the HiCN and instrumental methods. $\mathrm{P}<0.01$ was considered to indicate statistical significance.

\section{Results}

Laboratory and clinical features of neonatal serum samples. As presented in Table I, the content of serum total bilirubin in newborns within 25-120 h of birth was significantly higher compared with that in newborns within $24 \mathrm{~h}$ of birth $(\mathrm{P}<0.01)$. When NSE was detected, the birth time of the newborn was mainly distributed within $24 \mathrm{~h}$. However, the serum samples of newborns within $24 \mathrm{~h}$ of birth appeared to be hemolyzed, and the concentration of $\mathrm{Hb}$ in most sera was $>2 \mathrm{~g} / \mathrm{l}$.

Standard curves of $\mathrm{Hb}$. The standard curve of the Hb concentration in whole blood was $\mathrm{Hb}_{\text {blood }}=371.6900 \times \mathrm{x}_{540 \mathrm{~nm}}+1.7835$ $(\mathrm{r}=0.9991)$ according to the colorimetric analysis of a standard solution. In hemolyzed neonatal serum samples, the standard curve was $\mathrm{Hb}_{\text {serum }}=34.7690 \times \mathrm{A}_{540 \mathrm{~nm}}+0.2492$ ( $\left.\mathrm{r}=0.9996\right)$.

Correlation between the changes in concentrations of $\mathrm{Hb}$ and NSE. The individual constant of NSE for hemolyzed neonatal serum samples was the ratio between the change of
NSE to the Hb content in hemolyzed neonatal serum samples prior to and following addition of individually frozen-thawed RBCs of newborns. The individual constants of NSE in the 86 hemolyzed neonatal serum samples were $25.15 \pm 3.94 \mathrm{mg} / \mathrm{g}$ $\mathrm{Hb}$. Based upon the P-P plot analysis, the individual constants of NSE were normally distributed (Fig. 1A and B); the same result was obtained with D'Agostino's test $(\mathrm{P}=0.314$; data not shown). The changes in the concentration of NSE in sera prior to and following addition of individually frozen-thawed RBCs were significantly correlated with the changes in the concentration of $\mathrm{Hb}$ (Fig. 1C); the correlation of concentration variation between NSE and $\mathrm{Hb}$ in hemolyzed neonatal sera was $\Delta \mathrm{NSE}_{\text {serum }}=1.8594+24.0670 \times \mathrm{xb}_{\mathrm{HiCN}}\left(\mathrm{r}^{2}=0.8045, \mathrm{P}<0.001\right)$.

Comparison of the NSE results corrected by two different correction methods. The corrected NSE results from the individual constant group and correction formula group were compared with hemolyzed serum NSE results (Fig. 2A). There was no statistically significant difference in corrected NSE results between the individual constant and correction formula groups ( $\mathrm{Z}=-1.645, \mathrm{P}=0.100$; Fig. 2B). Additionally, the results demonstrated that the corrected NSE results from the individual constant group were significantly correlated with those of the correction formula group ( $\mathrm{r}=0.928, \mathrm{P}<0.001$; Fig. 2C). The $95 \%$ confidence interval results for NSE corrected with the formula were in the range of $-5.98-10.98 \mathrm{mg} / \mathrm{g} \mathrm{Hb}$, which were comparable with the results of NSE corrected by individual constants (Fig. 3).

Correlation between HiCN and instrument tests. The concentration of $\mathrm{Hb}$ in hemolyzed serum samples was measured by the 

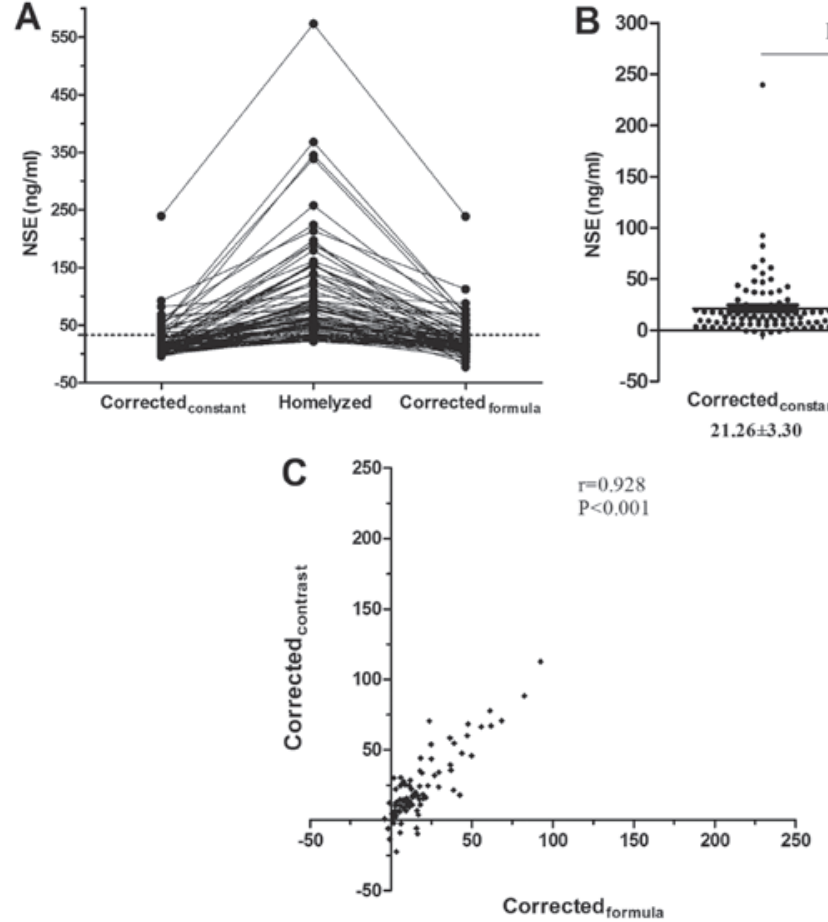

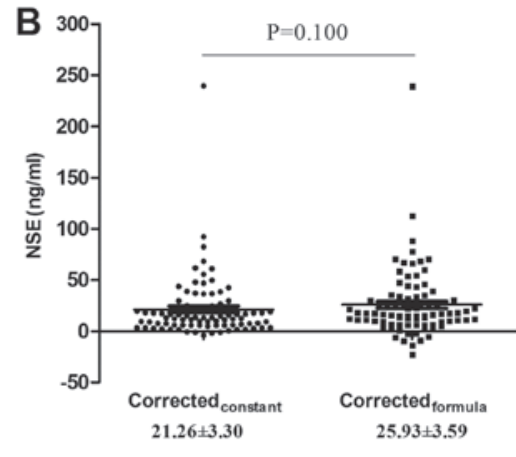

$25.93 \pm 3.59$

Figure 2. Comparison of NSE results corrected by individual constants and formula. (A) Graph of the corrected NSE results based on individual constants and the corrected NSE results using the correction formula in hemolyzed neonatal serum samples. (B) There was no statistically significant difference between the NSE concentrations following correction based upon the two different correction methods $(\mathrm{Z}=-1.645, \mathrm{P}=0.100)$. $(\mathrm{C}) \mathrm{Correlation}$ analysis demonstrated that the NSE results corrected by individual constants was significantly correlated with the those corrected with the formula $(r=0.928$, $P<0.001)$. NSE, neuron-specific enolase.

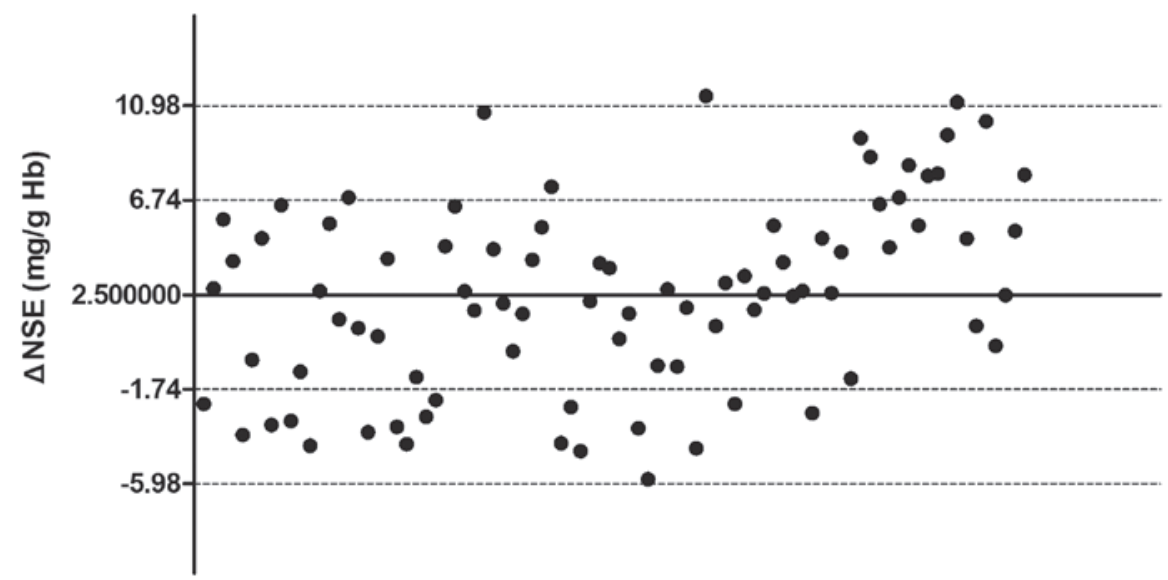

Figure 3. Absolute differences between NSE results in hemolyzed neonatal sera corrected by the formula and by individual constants. The value of $\Delta$ NSE $(\mathrm{mg} / \mathrm{g} \mathrm{Hb})$ obtained by calculating the ratio of the difference of NSE results was corrected by the formula minus the NSE results corrected by the individual constant to the $\mathrm{Hb}$ concentration in hemolyzed neonatal serum samples. The $95 \%$ confidence interval values were within the range of $-5.98 \sim 10.98 \mathrm{mg} / \mathrm{g} \mathrm{Hb}$. NSE, neuron-specific enolase; Hb, hemoglobin.

$\mathrm{HiCN}$ and instrumental methods. The content of $\mathrm{Hb}$ measured by the HiCN method was significantly correlated with that measured by the instrumental method (Fig. 4); the linear regression formula of $\mathrm{Hb}$ measured by the instrumental method compared with $\mathrm{HiCN}$ was $\mathrm{Hb}_{\mathrm{instr}}=0.9816 \times \mathrm{Hb}_{\mathrm{HiCN}}+0.5596$ $\left(\mathrm{r}^{2}=0.9924, \mathrm{P}<0.001\right)$.

Correction formulas. According to the association between the changes in NSE and $\mathrm{Hb}$ content in neonatal serum, as well as the correlation between the two methods for the determination of $\mathrm{Hb}$, the correction formulas for the determination of NSE in hemolyzed neonatal serum were $\mathrm{NSE}_{\text {corr }}=\mathrm{NSE}_{\text {meas }}-24.0670 \mathrm{x}$

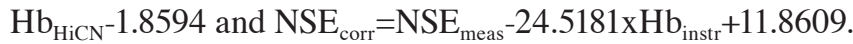

\section{Discussion}

The present study described the effect of hemolysis on the quantitative results of NSE in hemolyzed neonatal serum and proposed a correction formula for the quantitative results of NSE in hemolyzed neonatal serum. The correction formula cannot be applied to all newborns, particularly those with serum samples collected more than $24 \mathrm{~h}$ after birth, and 


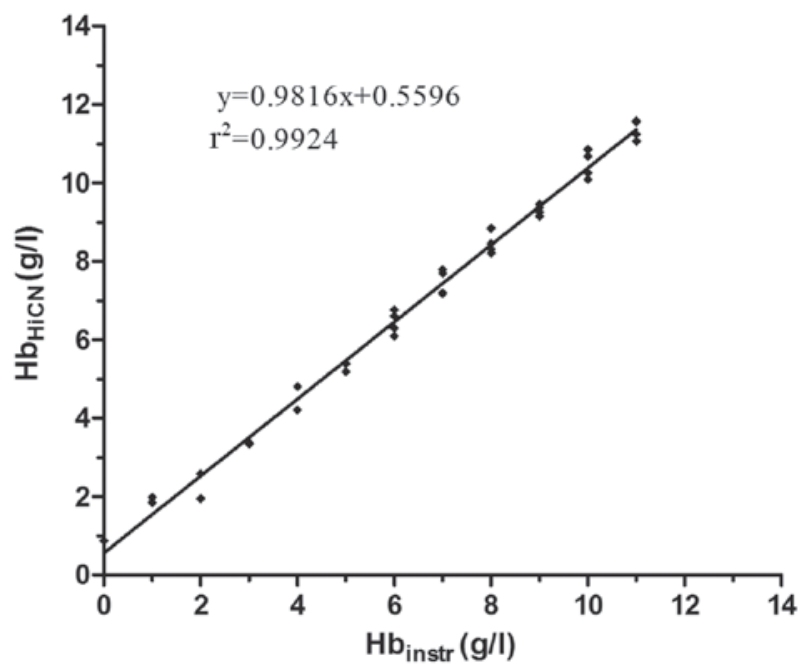

Figure 4. Concentrations of $\mathrm{Hb}$ in serum samples were measured with the $\mathrm{HiCN}$ and instrumental methods. The concentration of $\mathrm{Hb}$ measured by HiCN was significantly correlated with that measured by the instrumenta method $\left(r^{2}=0.9924, \mathrm{P}<0.001\right)$. HiCN, hemoglobin cyanide; Hb, hemoglobin.

cannot achieve true NSE results in hemolyzed neonatal sera. However, compared with the quantitative results of NSE or the estimated results of NSE based upon the pediatrician's experience with hemolyzed neonatal sera, the corrected NSE results were closer to the true value, and thus have potential in aiding pediatricians to evaluate the presence, severity and prognosis of HIE, particularly for newborns within $24 \mathrm{~h}$ of birth.

Due to differences in metabolism and half-life, investigating the association between the changes of NSE and $\mathrm{Hb}$ in vivo and the occurrence of physiological hemolysis in newborns is difficult, particularly during the period of large-scale metabolic conversion of $\mathrm{Hb}$ to bilirubin in the reticuloendothelial system of the liver, spleen and marrow $(14,15)$. Not only the association between the changes of NSE and $\mathrm{Hb}$ needs to be considered, but also the association between the changes of $\mathrm{Hb}$ and bilirubin. The corrected NSE results may be far from the true results. The degree of hemolysis of erythrocytes and the concentration of bilirubin in the serum of newborns exhibits a sharp increase on the third day and a slight decrease on the fifth day of birth (16). Accordingly, in the current study, the quantitation of total bilirubin in the serum of newborns within $24 \mathrm{~h}$ was higher compared with that in newborns aged 2 to 5 days old. This finding demonstrates that neonatal physiological hemolysis may occur or that $\mathrm{Hb}$ metabolic conversion may occur after $24 \mathrm{~h}$. In addition, more than $90 \%$ of clinical orders to measure NSE in serum were made within $24 \mathrm{~h}$ of the neonate's birth; and for more than $80 \%$ of newborns born within $24 \mathrm{~h}$, their degree of hemolysis of sera was greater than $1 \mathrm{~g} / \mathrm{l} \mathrm{Hb}$. These investigations demonstrate that i) establishing a correction formula for NSE in serum of newborns born within $24 \mathrm{~h}$ may account for most neonates; ii) establishing a correction formula for NSE in serum for newborns is critical; and iii) in most cases, a new blood sample from newborns obtained within $24 \mathrm{~h}$ of birth may improve the situation of hemolysis. Perinatal HIE involves two distinct phases: Immediate primary neuronal death associated with cellular hypoxia and depletion of energy stores; and a secondary phase of delayed neuronal death (at approximately $6 \mathrm{~h}$ ) associated with reperfusion injury (17). Establishing correct judgment and treatment is critical for the prognosis of newborns with HIE before $6 \mathrm{~h}$ of life (18). Overall, the present study established a correction formula for NSE in serum obtained from newborns within $24 \mathrm{~h}$ of birth.

Photometric determination of $\mathrm{HiCN}$ is recommended as the standard method for the quantitative determination of $\mathrm{Hb}$ in blood. If any other method is used, it should be compared with the HiCN method (19). In addition, when a spectrophotometer is used, the blood should be appropriately diluted (for example, 1:251, $20 \mu \mathrm{l}$ blood in $5 \mathrm{ml}$ reagent) (19). In the current study, because of the low level of $\mathrm{Hb}$ in neonatal sera, the dilution ratio was reduced (1:26, $100 \mu \mathrm{l}$ serum in $2.5 \mathrm{ml}$ reagent) to increase the sensitivity of $\mathrm{HiCN}$ in quantitating $\mathrm{Hb}$ in neonatal serum samples, and a best fit line of the concentration of $\mathrm{Hb}$ was obtained with the optical density at $\lambda=540 \mathrm{~nm}$ and an $r^{2}=0.9996$.

The reference range of NSE in neonatal serum in our laboratory is $0.00-18.00 \mathrm{mg} / 1$, determined from NSE data when NSE testing was performed at our laboratory, and the range of inter-individual variability of NSE with $\mathrm{Hb}$ is $25.15 \pm 3.94 \mathrm{mg} / \mathrm{g} \mathrm{Hb}$. This observation indicates that more than $80 \%$ of newborns may have different degrees of misinterpretation of their NSE results, particularly when the pediatrician does not consider the effect of hemolysis on the results of NSE. When verifying the performance of the correction formula, the concentration of NSE in all 86 hemolyzed neonatal serum samples exceeded the upper limit of the normal range prior to correction; in comparison, the ratios for exceeding the upper limit of the normal range were 34.88 and $44.19 \%$ for corrections by individual constants and the correction formula, respectively. There was no significant difference between those two groups of correction results, and thus the correction formula may be used to correct the concentration of NSE in hemolyzed neonatal sera. However, it should be highlighted that approximately 64,31 and $5 \%$ of corrected results for NSE may exhibit a maximum difference of 6.74, 10.98 and greater than $10.99 \mathrm{mg} / \mathrm{g} \mathrm{Hb}$, respectively, although these results were comparable with the results of NSE corrected by individual constants.

Due to the complexity of the HiCN method for detecting $\mathrm{Hb}$ in the serum of newborns, correlation analysis was used to evaluate the degree of consistency of the $\mathrm{HiCN}$ with an instrumental method, and the results indicated a high degree of correlation $\left(r^{2}=0.9924\right)$ between the methods. The instrument method could be used to quantify $\mathrm{Hb}$ in the serum of newborns, followed by the concentration of NSE with the correction formula. However, there was a maximum difference of $1 \mathrm{~g} / \mathrm{l} \mathrm{Hb}$ between the two methods, equivalent to an approximately $25.86 \mathrm{mg} / 1 \mathrm{NSE}$ difference, regardless of the degree of hemolysis in the serum of newborns.

In conclusion, the use of a correction formula aided to reduce the effects of hemolysis on NSE results. The present data suggested that the corrected NSE results were closer to the true value and may aid pediatricians evaluate the presence, severity and prognosis of HIE, particularly for newborns within $24 \mathrm{~h}$ of birth. 


\section{Acknowledgements}

The authors are thankful to Professor Xiaobing Tian from North Sichuan Medical College (Nanchong, China) for his assistance with the data analysis.

\section{Funding}

The current study was supported by grants from the Department of Science and Technology of Sichuan Province (grant no. 2016JY0171), and the International Science and Technology Cooperation Program of China (grant no. 2015DFA30420).

\section{Availability of data and materials}

The datasets used and/or analyzed during the current study are available from the corresponding author on reasonable request.

\section{Author's contributions}

QW and GW collected subjects, performed the experiments of $\mathrm{Hb}$ quantitation, neonatal serum NSE quantitation and correlation tests for the 86 neonatal serum samples, and prepared and wrote the first draft of this paper. XL performed statistical analyses and edited the manuscript. XG, QD and FL reviewed total bilirubin resultsand clinical order time and edited the manuscript. QF and GZ performed the Hb quantitation of the 280 neonatal serum samples. DW planned and designed the study. All authors read and approved the final manuscript.

\section{Ethical approval and consent to participate}

This research programme was approved by the Ethics Committee of the Affiliated Hospital of North Sichuan Medical University and was consented by the parents or guardians of participants enrolled for the purposes of the current study.

\section{Consent for publication}

Consent for publication of relevant data was obtained from the parents or guardians of enrolled participants on the basis of anonymization of all personal data.

\section{Competing interests}

The authors declare that they have no competing interests.

\section{References}

1. Douglas-Escobar M and Weiss MD: Hypoxic-ischemic encephalopathy: A review for the clinician. JAMA Pediatr 169: 397-403, 2015.

2. Agut T, León M, Rebollo M, Muchart J, Arca G and Garcia-Alix A: Early identification of brain injury in infants with hypoxic ischemic encephalopathy at high risk for severe impairments: Accuracy of MRI performed in the first days of life. BMC Pediatr 14: 177-183, 2014.
3. Pierrat V, Haouari N, Liska A, Thomas D, Subtil D and Truffert P; Groupe d'Etudes en Epidémiologie Périnatale: Prevalence, causes, and outcome at 2 years of age of newborn encephalopathy: Population based study. Arch Dis Child Fetal Neonatal Ed 90: F257-F261, 2005.

4. Filippi L, Fiorini P, Daniotti M, Catarzi S, Savelli S, Fonda C, Bartalena L, Boldrini A, Giampietri M, Scaramuzzo R, et al: Safety and efficacy of topiramate in neonates with hypoxic ischemic encephalopathy treated with hypothermia (NeoNATI). BMC Pediatr 12: 144-154, 2012.

5. Shang Y, Mu L, Guo X, Li Y, Wang L, Yang W, Li S and Shen Q: Clinical significance of interleukin-6, tumor necrosis factor- $\alpha$ and high-sensitivity C-reactive protein in neonates with hypoxic-ischemic encephalopathy. Exp Ther Med 8: 1259-1262, 2014.

6. Douglas-Escobar $M$ and Weiss MD: Biomarkers of hypoxic-ischemic encephalopathy in newborns. Front Neurol 3: 144, 2012.

7. Tolan NV, Vidal-Folch N, Algeciras-Schimnich A, Singh RJ and Grebe SK: Individualized correction of neuron-specific enolase (NSE) measurement in hemolyzed serum samples. Clin Chim Acta 424: 216-221, 2013.

8. Berger RP: The use of serum biomarkers to predict outcome after traumatic brain injury in adults and children. J Head Trauma Rehabil 21: 315-333, 2006.

9. Guzel A, Er U, Tatli M, Aluclu U, Ozkan U, Duzenli Y, Satici O, Guzel E, Kemaloglu S, Ceviz A, et al: Serum neuron-specific enolase as a predictor of short-term outcome and its correlation with Glasgow Coma Scale in traumatic brain injury. Neurosurg Rev 31: 439-444, discussion 444-445, 2008.

10. Chabok SY, Moghadam AD, Saneei Z, Amlashi FG, Leili EK and Amiri ZM: Neuron-specific enolase and S100BB as outcome predictors in severe diffuse axonal injury. J Trauma Acute Care Surg 72: 1654-1657, 2012

11. Celtik C, Acunaş B, Oner N and Pala O: Neuron-specific enolase as a marker of the severity and outcome of hypoxic ischemic encephalopathy. Brain Dev 26: 398-402, 2004.

12. Marangos PJ, Campbell IC, Schmechel DE, Murphy DL and Goodwin FK: Blood platelets contain a neuron-specific enolase subunit. J Neurochem 34: 1254-1258, 1980.

13. National Committee for Clinical Laboratory Standards (NCCLS): Method Comparison and Bias Estimation Using Patient Samples; Approved Guideline-Second Edition. NCCLS document EP9-A2. NCCLS, Wayne, PA, 2002.

14. Nakajima H, Takemura T, Nakajima $\mathrm{O}$ and Yamaoka K: Studies on hemo $\alpha$-methenyl oxygenase. I. The enzymatic conversion of pyridine-hemichromogen and hemoglobin-haptoblobin into a possible precursor of biliverdin. J Biol Chem 238: 3784-3796, 1963.

15. Robinson SH and Koeppel E: Preferential hemolysis of immature erythrocytes in experimental iron deficiency anemia: Source of erythropoietic bilirubin formation. J Clin Invest 50: 1847-1853, 1971.

16. Richards JE, Goldbloom RB and Denton RL: Physiologic hyperbilirubinemia and hemolysis of erythrocytes by hydrogen peroxide solution in the newborn: Investigation of a possible relationship. Pediatrics 20: 92-97, 1957.

17. Gulczyńska E and Gadzinowski J: Therapeutic hypothermia for neonatal hypoxic-ischemic encephalopathy. Ginekol Pol 83: 214-218, 2012 (In Polish).

18. Horn AR, Swingler GH, Myer L, Linley LL, Raban MS, Joolay Y, Harrison MC, Chandrasekaran M, Rhoda NR and Robertson NJ: Early clinical signs in neonates with hypoxic ischemic encephalopathy predict an abnormal amplitude-integrated electroencephalogram at age 6 hours. BMC Pediatr 13: 52-62, 2013.

19. No authors listed: International committee for standardization in haematology. Recommendations for haemoglobinometry in human blood. Br J Haematol 13: 71-75, 1967. 